\title{
Difference of Glucose variability between Low Carbohydrate Diet (LCD) and Calorie Restriction (CR) \\ $\underline{\text { Hiroshi Bando }}^{1,2^{*}}$, Koji Ebe ${ }^{2,3}, \underline{\text { Tetsuo Muneta }}^{2,4}$ Masahiro Bando $^{5}$, $\underline{\text { Yoshikazu Yonei }}^{6}$
}

${ }^{1}$ Tokushima University / Medical Research, Tokushima, Japan

2 Japan Low Carbohydrate Diet Promotion Association, Kyoto, Japan

${ }^{3}$ Takao Hospital, Kyoto, Japan

${ }^{4}$ Muneta Maternity Clinic, Chiba, Japan

${ }^{5}$ Department of Nutrition and Metabolism, Institute of Biomedical Sciences, Tokushima University Graduate School, Tokushima, Japan

${ }^{6}$ Anti-Aging Medical Research Center, Graduate School of Life and Medical Sciences, Doshisha University, Kyoto, Japan

\section{Corresponding Author: Hiroshi Bando, MD, PhD, FACP}

Address: Tokushima University /Medical Research, Nakashowa 1-61, Tokushima 770-0943, Japan. Received date: 22 December 2018; Accepted date: 2 January 2019; Published date: 9 January 2019

Citation: Bando H, Ebe K, Muneta T, et al., "Difference of Glucose variability between Low Carbohydrate Diet (LCD) and Calorie Restriction (CR)". Asp Biomed Clin Case Rep, vol.2, no.s1: 415, 2019.

Copyright (C) 2019 Bando H, Ebe K, Muneta T, et al., This is an open access article distributed under the Creative Commons Attribution License, which permits unrestricted use, distribution, and reproduction in any medium, provided the original work is properly cited.

\section{Abstract}

Background: There have been lots of discussion and controversy concerning the difference between Low Carbohydrate Diet (LCD) and Calorie Restriction (CR). The important points include glucose variability, glucose-lowering effect, weight reduction degree and influence on lipid metabolism.

Subjects and Methods: Enrolled subjects were 47 patients with T2DM. Methods included the study for providing subjects CR meal with $60 \%$ carbohydrate on day 1-2 and LCD meal with $12 \%$ on day 314. Daily profile of blood glucose was studied seven times a day on day 2 and day 4 . Further, biomarkers including $\mathrm{HbA1c}$, average blood glucose, and $\mathrm{M}$ value were investigated and analyzed for mutual correlations.

Results: Subjects were categorized into 4 groups according to the average glucose value, which were $124 \mathrm{mg} / \mathrm{dL}, 160 \mathrm{mg} / \mathrm{dL}, 206 \mathrm{mg} / \mathrm{dL}$, and $281 \mathrm{mg} / \mathrm{dL}$, respectively. Data in 4 groups were as follows: Number; 12,12,12,11, Male/Female; 6/6, 3/9, 6/6, 5/6, mean age; 51.3, 60.9, 65.3, 60.6 years old, $\mathrm{HbA} 1 \mathrm{c} ; 6.1 \%, 7.1 \%, 8.0 \%, 8.9 \%$, fasting glucose on day $2 ; 109 \mathrm{mg} / \mathrm{dL}, 136 \mathrm{mg} / \mathrm{dL}, 178 \mathrm{mg} / \mathrm{dL}$, $224 \mathrm{mg} / \mathrm{dL}$, respectively. Daily profiles of blood glucose in 4 groups on day 4 were remarkably decreased than those of day 2. The levels of $M$ value indicating average blood glucose and mean amplitude of glycemic excursions (MAGE) on day 2 vs 4 were compared in 4 groups, which are 7.1 vs $10.5,39.7$ vs $5.0,139$ vs $15.7,367$ vs 88 , respectively. Correlations among $\mathrm{HbA1c}, \mathrm{M}$ value and average blood glucose showed significant correlations $(p<0.01)$.

Discussion and Conclusion: Obtained results showed that the distribution of daily profile of blood glucose in 4 groups is separated. Further similar tendency was observed in $\mathrm{HbA} 1 \mathrm{c}$ and $\mathrm{M}$ value. 
Citation: Bando H, Ebe K, Muneta T, et al., "Difference of Glucose variability between Low Carbohydrate Diet (LCD) and Calorie Restriction (CR)”. Asp Biomed Clin Case Rep, vol.2, no.s1: 4-15, 2019.

There was remarkable decrease of blood glucose from CR to LCD. These findings suggested that LCD would have remarkable efficacy for improving glucose variability. Furthermore, obtained findings could become basal and reference data for the developing research for CR and LCD.

Key words:

Glucose variability; Type 2 diabetes mellitus (T2DM); Low Carbohydrate Diet (LCD); Morbus value (M value); Calorie Restriction (CR)

Abbreviation:

LCD: Low Carbohydrate Diet; T2DM: Type 2 diabetes mellitus; CR: Calorie Restriction; IRI: Immunoreactive Insulin; M value: Morbus value; HOMA-R: Homeostasis Model Assessment of Insulin Resistance; HOMA- $\beta$ : Homeostasis Model Assessment of $\beta$ Cell Function.

\section{Introduction}

Diabetes has been increasing, and about 451 million people with diabetes are estimated to be present worldwide in 2017 [1]. The number will be expected to increase to 693 million by 2045 . Among the people who are estimated to have diabetes at present, almost half of people with diabetes are not diagnosed yet. Thus, it is crucial to deal with diabetes medically and socially [2].

With regard to the diagnosis and treatment for diabetes, there have been controversies in several diabetes societies $[3,4]$. There have been some discussions about the recommended level of $\mathrm{HbA} 1 \mathrm{c}$ that would be the goal for clinical management for diabetes, between the American Diabetes Association (ADA) and the American College of Physicians (ACP) in recent years [4,5]. From the clinical point of view, there have been diabetic variability with various heterogeneity. Then, we have to argue the adequate control situation in each diabetic patient $[5,6]$.

The basal treatment for diabetes has been nutritional therapy. The basal treatment for diabetes has been diet therapy, which is one of the three main treatment for diabetes including i) diet therapy, ii) exercise therapy, iii) antidiabetic agents or insulin for medicine. As to the diet therapy for diabetes, there have been discussions about Calorie Restriction (CR) and Low Carbohydrate Diet (LCD) which are categorized into two major nutritional characteristics nutrition's. Bernstein et al. has begun to present LCD in 1990' and applied LCD for the treatment of diabetes [7].

In succession, the report from the Dietary Intervention Randomized Controlled Trial (DIRECT) Group has been known widely [8]. They compared LCD, CR (Low-Fat Diet) and the Mediterranean diet, with the result of the predominance of LCD for 2 years. After that, the efficacy of LCD for 4 years of interventions was reported [9].

In contrast, authors and co-researchers have initiated LCD in Japan [10]. After that, we have developed the clinical efficacy of LCD through educational books and workshop for long [11]. Recently, Japan LCD promotion association has been established and its activities have continued [12]. We have also continued clinical research of LCD and CR and reported the significance and pathophysiological role of Ketone Bodies (KB) in the circumstances of the axis of fetus-placentanewborn-mother [13]. For patients with diabetes and Met-S and general people, we have presented three types of recommending LCD meals, such as super LCD, moderate LCD and petite LCD meals [14].

In this study, authors and colleagues have presented the comparison with $\mathrm{CR}$ meal and LCD meals for diabetic patients. Further, diabetic biomarkers including $\mathrm{HbA1c}, \mathrm{M}$ value, lipids were investigated for mutual correlations for clarifying the pathophysiology and glucose variability in diabetes. 
Citation: Bando H, Ebe K, Muneta T, et al., "Difference of Glucose variability between Low Carbohydrate Diet (LCD) and Calorie Restriction (CR)”. Asp Biomed Clin Case Rep, vol.2, no.s1: 4-15, 2019.

\section{Subjects and Methods}

In this study, the enrolled subjects were 47 patients, who were recently diagnosed as Type 2 Diabetes Mellitus (T2DM). They were admitted to the hospital for further evaluation and treatment of diabetes. Especially, the purpose of the educational admission method is to understand two types of meal. During staying in the hospital, they have an experience of taking calorie restriction (CR) and also low carbohydrate diet (LCD), consecutively. For this series of nutritional education, they understand what are CR and LCD like, and have the fundamental knowledge and practice for diabetes mellitus.

As to the detail of the methods, our research group has made our common diabetic formula protocol. It includes the diagnosis, examination, and treatment of the diabetic research program. The principle and the detail are as follows:

i) Concerning the diagnosis, the subjects in this study were diagnosed as T2DM in the recent period. We excluded specific types of diabetes, including type 1 diabetes mellitus (T1DM) or others. These patients with T2DM were not administered medicine for diabetes, which can influence glucose variability in daily profile and also postprandial glucose response.

ii) The protocol included 14 days of further evaluation and treatment for T2DM. They were admitted in the hospital and were given several examinations. On the next day of the admission, which is day 2 , they were drawn blood samples for fundamental examination after overnight fasting. The exams included complete blood count, renal and liver function test, lipids, and etc. Regarding examination items for diabetes, we ordered blood glucose level on fasting and postprandial time, as well as Immunoreactivity of Insulin (IRI), HbA1c, C-peptide, HOMA-R, HOMA- $\beta, M$ value were obtained for the study.

iii) In our protocol, nutritional therapy includes two kinds of diet. CR meal was provided in day 1 and 2 which has $1400 \mathrm{kcal} /$ day with the PFC ratio as 15: 25: 60 . This has been the standard
Japanese meal pattern recommended by the Japan Diabetes Association (JDA) [15].

iv) Successively, LCD meal was provided during day 3 to day 14 . It has a $1400 \mathrm{kcal} /$ day with the PFC ratio from day 3 to 14 with super LCD. The content has $12 \%$ of carbohydrate with $1400 \mathrm{kcal} /$ day with $12 \%$ of carbohydrate ratio. This has been called as super-LCD, which has been well-known and popular in Japan. In our protocol, there are three types of LCD meals, which are super LCD, standard LCD with $26 \%$ of carbohydrate and petite LCD with $40 \%$ of carbohydrate.

v) Research protocol included the comparison of the values in several biomarkers between day 2 and day 4, and between day 2 and day 14 . The former included the comparison of CR and LCD meals on day 2 and day 4 . The latter included the comparison of lipids such as triglyceride, HDL-cholesterol and LDLcholesterol.

\section{Glucose profile:}

In order to clarify the daily profile of blood glucose, we measured blood glucose 7 times from morning until night. The times were 0800, 1000, 1200, 1400, 1700, 1900 and 2200h. CR meal was given on day 1 and day 2 , and a daily profile of blood glucose was studied on day 2 . Similarly, LCD meal was given during day 3 and 14 , and a daily profile of blood glucose was studied on day 4. Glucose variability was investigated between day 2 and day 4 . According to the obtained data of blood glucose 7 times a day, blood glucose in average and $M$ value were calculated by the calculation equation of the formula on $\mathrm{M}$ value $[16,17]$.

\section{$M$ value:}

It is $M$ value that has been evaluated as one of the useful biomarkers for glucose variability. M value shows two valuable meaningful data. The former means the value of the average blood glucose per day, and the latter means the width of the glucose fluctuation, which reveals the Mean Amplitude of Glycemic Excursions (MAGE) [18-20]. Both data obtained can 
Citation: Bando H, Ebe K, Muneta T, et al., "Difference of Glucose variability between Low Carbohydrate Diet (LCD) and Calorie Restriction (CR)”. Asp Biomed Clin Case Rep, vol.2, no.s1: 4-15, 2019.

speculate the general glucose variability in a day.

Thus, $M$ value can be revealed as a numerical value which includes two valuable markers. One is the degree of elevated blood glucose in average, and another is the increased swinging of the variability of blood glucose. By applying the mathematics method, we can calculate $M$ value as the equation of the logarithmic transformation. As to the significance of $M$ value, it means the degree of the glucose deviation from the ideal blood glucose profile in a day [19-21].

The calculation way for the $M$ value includes three processes. The first one shows the basal equation, which is $\mathrm{M}=\mathrm{M}^{\mathrm{BS}}+\mathrm{M}^{\mathrm{W}}$. M value means the total value of both $\mathrm{M}^{\mathrm{BS}}$ and $\mathrm{M}^{\mathrm{W}}$. The second shows the $\mathrm{M}^{\mathrm{W}}$, that expresses (maximum blood glucose - minimum glucose)/20. The last one revealed that $M^{B S}$ is the mean of MBSBS. Summarizing these into one equation, MBSBS has been the individual M-value for each blood glucose, which is calculated as (absolute value of $\left[10 \times \log (\text { blood glucose level/120)] })^{3}\right.$ [19-21]

Generally, there has been clinically estimation of judgment for glucose variability from the elevated level of $M$ value. For the result of $M$ value, the standard normal range has been less than 180 , and the borderline is 180 and more than 180 and less than 320, and the abnormal range is 320 and more than 320 .

\section{Ethical Considerations:}

This study has been fundamentally performed in compliance with the ethical principles based on the Declaration of Helsinki. Moreover, the additional commentary was conducted on the Ethical Guidelines for Research in the medical field for Humans and in accordance with the Good Clinical Practice (GCP). They were found associated with the ongoing consideration for the protection of human rights. Further, "Ethical Guidelines for Epidemiology Research" was applied as an adequate guideline. It was presented in Japan by the Ministry of Education, Culture, Sports, Science, and Technology and the Ministry of Health, Labor and Welfare.
The author and our researchers have established an ethical committee. As regard to the discussion for the medical and ethical problems, included professions were a medical doctor, nurse, pharmacist, nutritionist and other experts in the legal specialty. For the current investigation, our discussion resulted in appropriate and valid, with the agreements. From the point of patients' view, the informed consents and written document agreements have been obtained from all the subjects. Current investigation has been registered by the National University Hospital Council of Japan (ID: \#R000031211).

\section{Results \\ Fundamental data:}

In the current study, 47 patients with T2DM were enrolled and their fundamental data of several biomarkers were shown in Table-1. Average ages in 4 groups were from 51.3 to 65.3 years old, and the number of male/female was $20 / 27$, respectively. The grouping was performed by the level of average blood glucose, which were $124 \mathrm{mg} / \mathrm{dL}, 160 \mathrm{mg} / \mathrm{dL}$, $206 \mathrm{mg} / \mathrm{dL}, 281 \mathrm{mg} / \mathrm{dL}$, respectively. HbA1c value in 4 groups was $6.1,7.1,8.0$ and $8.9 \%$, respectively.

The average blood glucose 2 hours after breakfast on day 2 vs day 4 in 4 groups were as follows: 141.6 vs $116.6 \mathrm{mg} / \mathrm{dL}, 194.8$ vs 151.2 $\mathrm{mg} / \mathrm{dL}, 271.3$ vs $181.8 \mathrm{mg} / \mathrm{dL}$ and 323.0 vs $226.0 \mathrm{mg} / \mathrm{dL}$, respectively.

The median value of the immunoreactivity of insulin (IRI) on fasting in each group was 6.7, $7.5,4.1$ and $5.6 \mu \mathrm{U} / \mathrm{mL}$ respectively. The value of HOMA- $\beta$ in each group was $76.5,29.3,21.3$ and 11.8 , respectively. The median value of triglyceride on fasting on day 2 vs day 14 in 4 groups were as follows: 120 vs $73 \mathrm{mg} / \mathrm{dL}, 107$ vs $86 \mathrm{mg} / \mathrm{dL}, 116$ vs $85 \mathrm{mg} / \mathrm{dL}$ and 190 vs 124 $\mathrm{mg} / \mathrm{dL}$, respectively. 
Citation: Bando H, Ebe K, Muneta T, et al., "Difference of Glucose variability between Low Carbohydrate Diet (LCD) and Calorie Restriction (CR)". Asp Biomed Clin Case Rep, vol.2, no.s1: 4-15, 2019.

\begin{tabular}{|c|c|c|c|c|c|}
\hline Group & & Group 1 & Group 2 & Group 3 & Group 4 \\
\hline \multirow{3}{*}{ Subjects } & Number & 12 & 12 & 12 & 11 \\
\hline & Sex (male/female) & $6 / 6$ & $3 / 9$ & $6 / 6$ & $5 / 6$ \\
\hline & Age (years old.) & $51.3 \pm 13.1$ & $60.9 \pm 16.5$ & $65.3 \pm 8.7$ & $60.6 \pm 5.7$ \\
\hline \multirow{5}{*}{ Glucose } & HbA1c (\%) & $6.1 \pm 0.9$ & $7.1 \pm 0.9$ & $8.0 \pm 1.0$ & $8.9 \pm 1.2$ \\
\hline & $\begin{array}{l}\text { Glucose }(0) \text { on day } 2 \\
(\mathrm{mg} / \mathrm{dL})\end{array}$ & $109.2 \pm 16.2$ & $135.5 \pm 18.1$ & $177.7 \pm 36.3$ & $220.4 \pm 29.5$ \\
\hline & $\begin{array}{l}\text { Glucose (120) on day } \\
2(\mathrm{mg} / \mathrm{dL})\end{array}$ & $141.4 \pm 32.0$ & $194.8 \pm 34.9$ & $271.3 \pm 36.5$ & $323.0 \pm 45.0$ \\
\hline & $\begin{array}{l}\text { Glucose }(0) \text { on day } 4 \\
(\mathrm{mg} / \mathrm{dL})\end{array}$ & $91.7 \pm 15.4$ & $122.1 \pm 14.3$ & $142.2 \pm 19.3$ & $177.6 \pm 22.0$ \\
\hline & $\begin{array}{l}\text { Glucose (120) on day } \\
4(\mathrm{mg} / \mathrm{dL})\end{array}$ & $116.6 \pm 15.4$ & $151.2 \pm 15.3$ & $181.8 \pm 17.6$ & $226.0 \pm 29.4$ \\
\hline \multirow{3}{*}{ Resistance } & $\begin{array}{l}\text { Insulin }(0) \text { on day } 2 \\
(\mu \cup / m L)\end{array}$ & $6.7[2.6-11.7]$ & $7.5[3.9-9.5]$ & $4.1[3.5-9.0]$ & $\begin{array}{c}5.6[3.3- \\
7.3]\end{array}$ \\
\hline & HOMA-R & $2.2[0.7-3.3]$ & $2.3[1.2-3.3]$ & $2.1[1.2-3.9]$ & $\begin{array}{l}3,0[1.9- \\
4.3]\end{array}$ \\
\hline & HOMA- $\beta$ & $\begin{array}{c}76.5[24.1- \\
83.1]\end{array}$ & $\begin{array}{c}29.3[19.7- \\
50.3]\end{array}$ & $\begin{array}{c}21.3[10.2- \\
29.7]\end{array}$ & $\begin{array}{c}11.8[7.6- \\
16.6]\end{array}$ \\
\hline \multirow{6}{*}{ Lipids } & $\begin{array}{l}\text { Triglyceride on day } 2 \\
(\mathrm{mg} / \mathrm{dL})\end{array}$ & $120[69-155]$ & $\begin{array}{l}107[77- \\
126]\end{array}$ & $\begin{array}{c}116[77- \\
134]\end{array}$ & $\begin{array}{c}190[169- \\
257]\end{array}$ \\
\hline & $\begin{array}{l}\text { Triglyceride on day } 14 \\
(\mathrm{mg} / \mathrm{dL})\end{array}$ & 73 [57 - 103] & 86 [ $75-94]$ & $85[58-107]$ & $\begin{array}{c}124[95- \\
152]\end{array}$ \\
\hline & $\begin{array}{l}\text { HDL-Chol on day } 2 \\
(\mathrm{mg} / \mathrm{dL})\end{array}$ & 57 [51 - 75] & $50[47-67]$ & 74 [ 65 - 78] & $60[44-73]$ \\
\hline & $\begin{array}{l}\text { HDL-Chol on day } 14 \\
(\mathrm{mg} / \mathrm{dL})\end{array}$ & $48[44-61]$ & $47[43-64]$ & $60[46-74]$ & $46[41-65]$ \\
\hline & $\begin{array}{l}\text { LDL-Chol on day } 2 \\
(\mathrm{mg} / \mathrm{dL})\end{array}$ & 120 [106 - 147] & $\begin{array}{l}115[84- \\
134]\end{array}$ & $\begin{array}{l}151[112- \\
164]\end{array}$ & $\begin{array}{c}155[141- \\
186]\end{array}$ \\
\hline & $\begin{array}{l}\text { LDL-Chol on day } 14 \\
(\mathrm{mg} / \mathrm{dL})\end{array}$ & 133 [113 - 153] & $\begin{array}{c}136[118- \\
165]\end{array}$ & $\begin{array}{c}136[122- \\
152]\end{array}$ & $\begin{array}{c}179 \text { [142 - } \\
199]\end{array}$ \\
\hline \multicolumn{6}{|c|}{ The results were expressed by mean \pm SD or median $[25 \%-75 \%]$. } \\
\hline
\end{tabular}


Citation: Bando H, Ebe K, Muneta T, et al., "Difference of Glucose variability between Low Carbohydrate Diet (LCD) and Calorie Restriction (CR)”. Asp Biomed Clin Case Rep, vol.2, no.s1: 4-15, 2019.

Daily profile of blood glucose:

Daily profile of blood glucose in 4 groups was investigated (Fig-1). Blood glucose variability in 4 groups showed the parallel pattern. Among them, blood glucose value is the lowest in group 1 and is the highest in group 4. Acute elevation of blood glucose was observed from $0800 \mathrm{~h}$ to $1000 \mathrm{~h}$ on the morning of day 2. The evaluation degree became smaller on day 4 compared with that of day 2 .

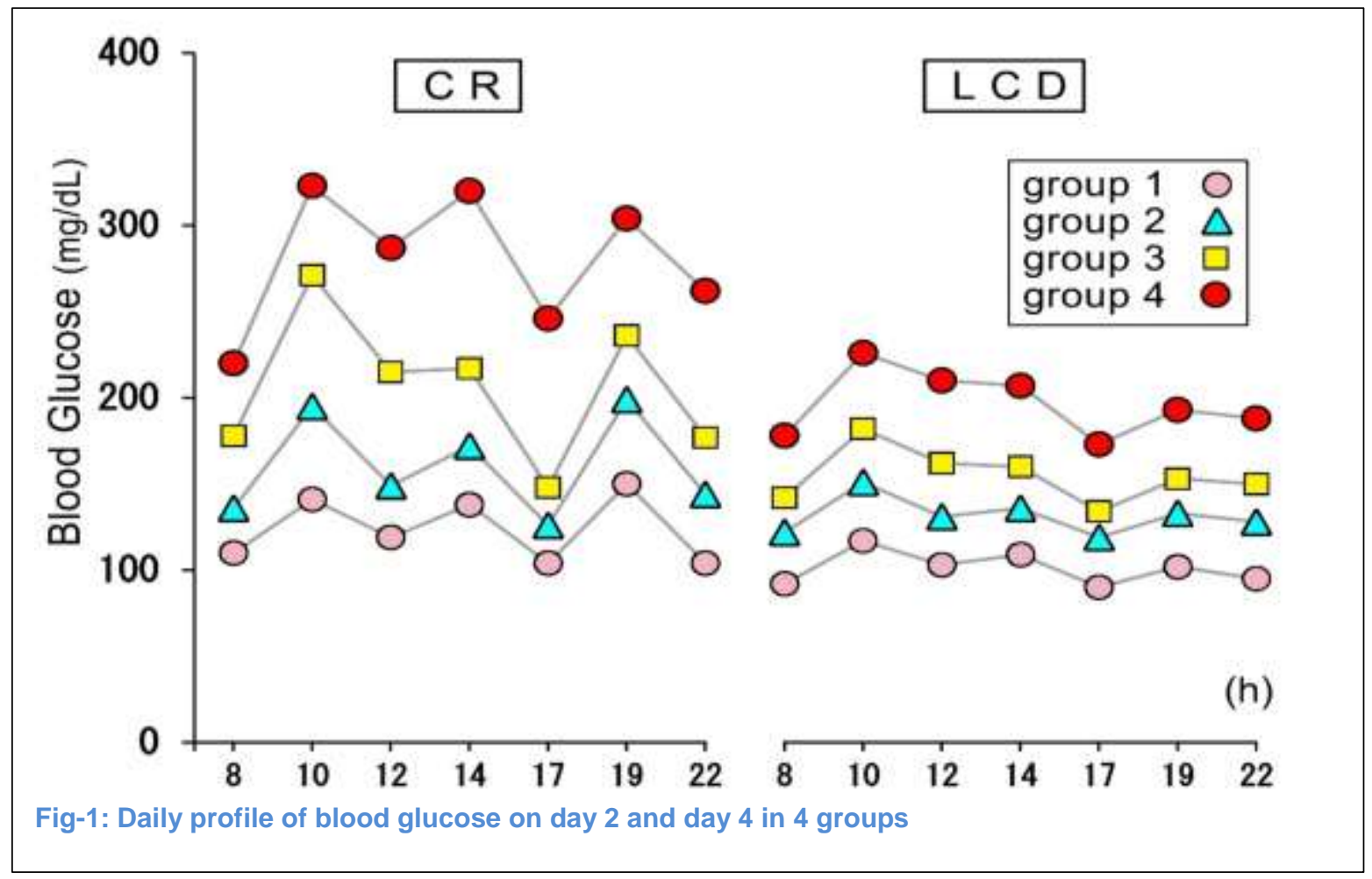

$H b A 1 c$ and $M$ value:

Comparison of $\mathrm{HbA1c}$ and $\mathrm{M}$ value in 4 groups are shown in Fig-2. The median value of $\mathrm{HbA1c}$ was increased from group 1 to 4 (Fig-2a). Obtained data of $M$ value was increased from group 1 to 4 (Fig-2b).
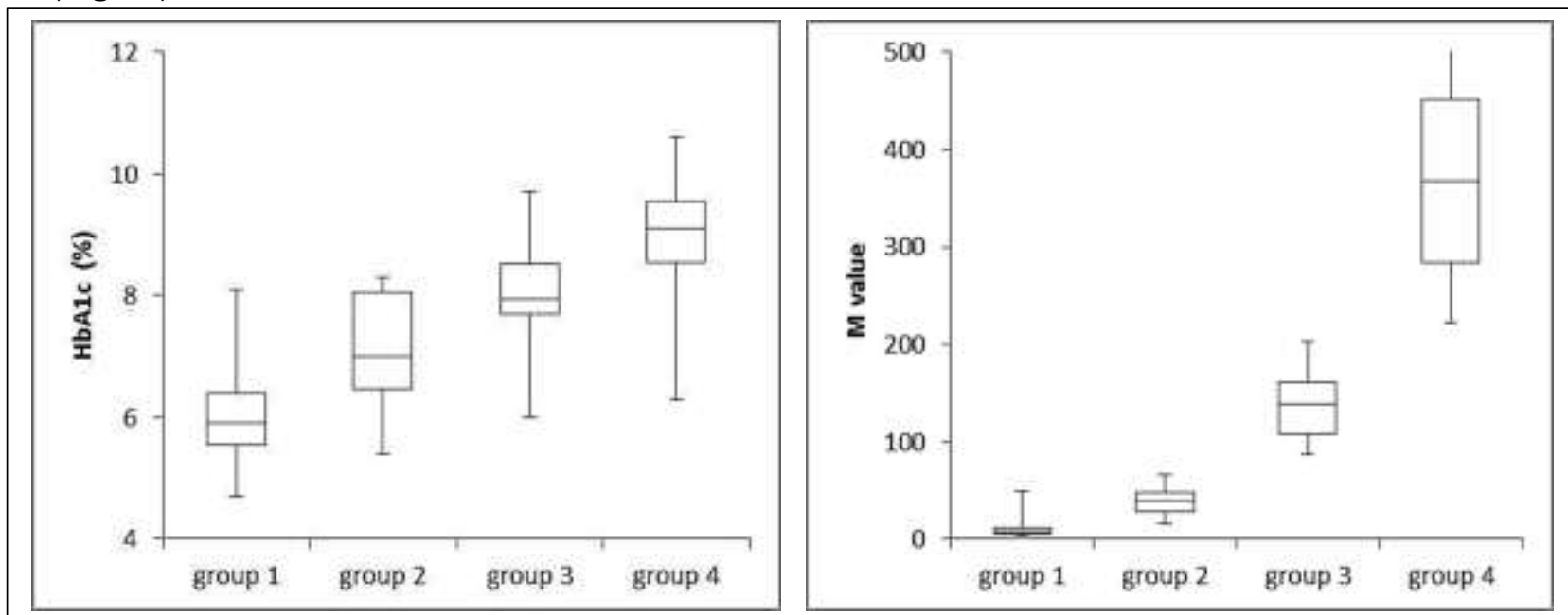

Fig- 2: Comparison of $\mathrm{HbA1C}$ and $\mathrm{M}$ value in 4 groups

Fig- 2a: HbA1c value was increased from group 1 to 4 Fig- 2b: M values was increased from group 1 to 4. 
Citation: Bando H, Ebe K, Muneta T, et al., "Difference of Glucose variability between Low Carbohydrate Diet (LCD) and Calorie Restriction (CR)”. Asp Biomed Clin Case Rep, vol.2, no.s1: 4-15, 2019.

Regarding median values in groups 1 to 4 , a linear increase was observed in $\mathrm{HbA} 1 \mathrm{c}$ and a sharp increase in $\mathrm{M}$ value which is like a quadratic curve.

HOMA-R and HOMA- $\beta$ :

Comparison of HOMA-R and HOMA- $\beta$ in 4 groups is shown in Fig-3. The median value of HOMA-R did not show the difference in 4 groups (Fig-3a). In contrast, the median value of HOMA- $\beta$ decreased from group 1 to 4 with a remarkable degree (Fig-3b).

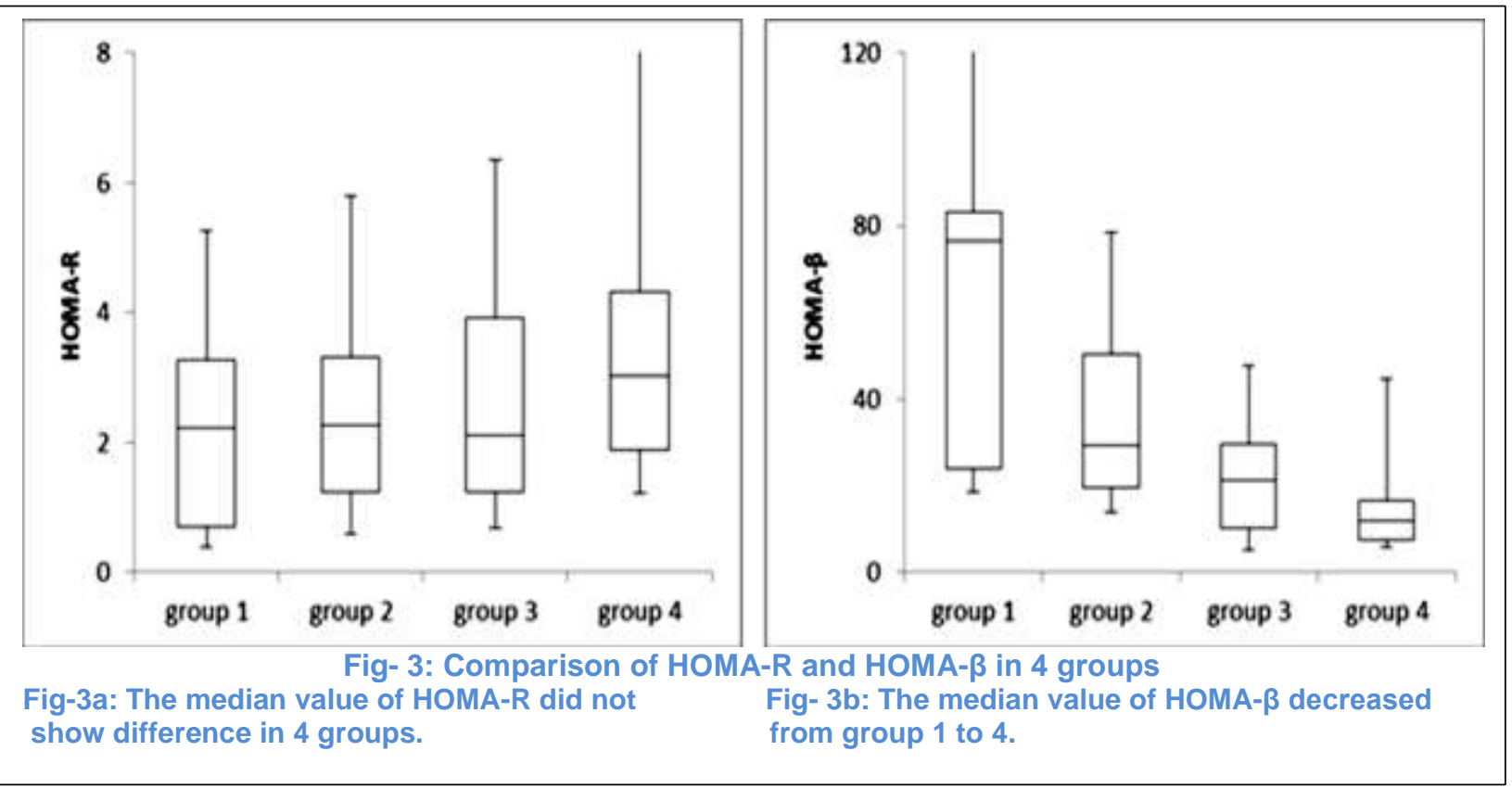

Changes in average blood glucose:

Changes in average blood glucose from day 2 to day 4 in 4 groups were shown in Fig-4. Subjects have CR meal on day 1 and 2, and LCD meal on day 3-14. In group 1-4, the median value of daily blood glucose in average decreased from day 2 to day 4 .

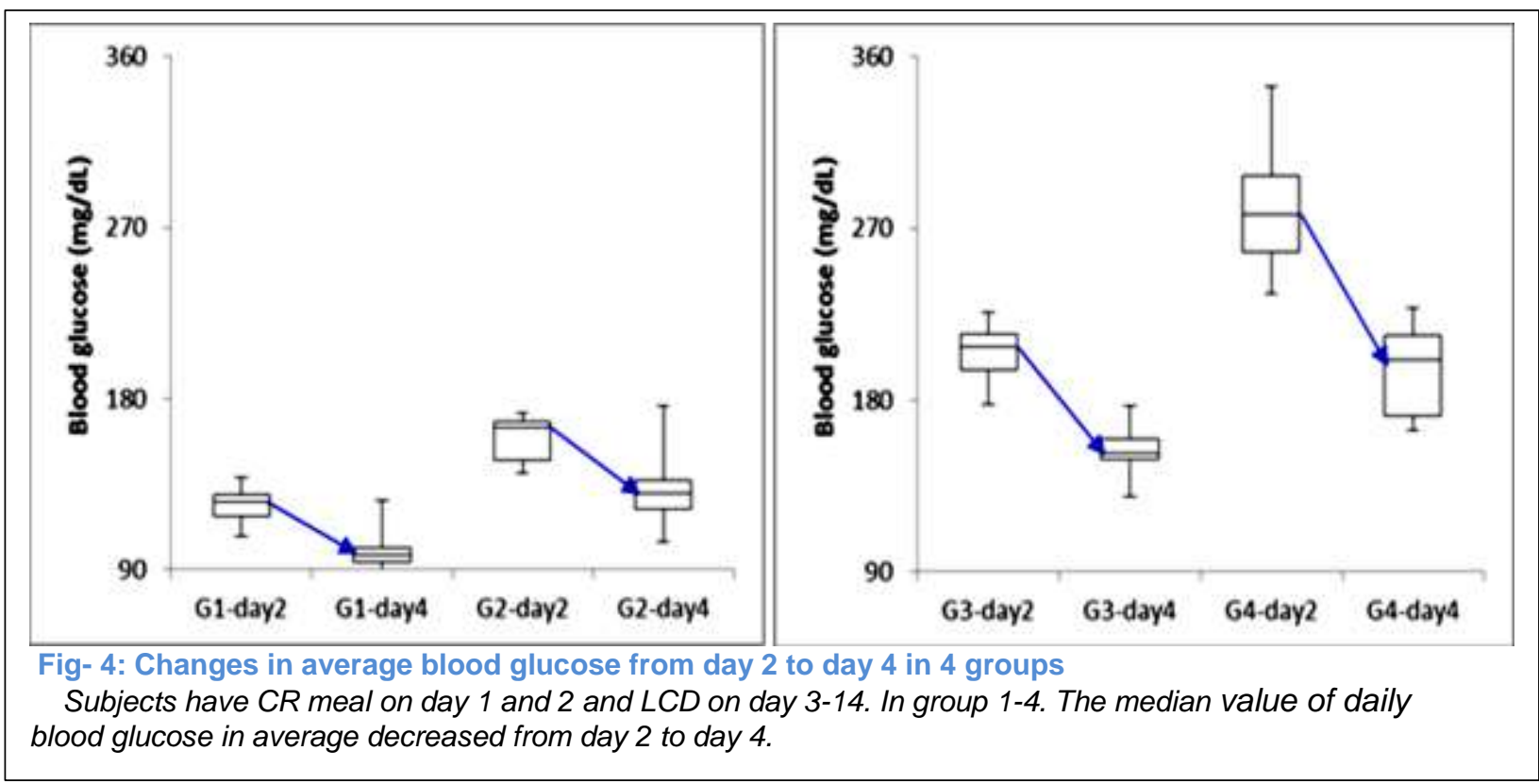


Citation: Bando H, Ebe K, Muneta T, et al., "Difference of Glucose variability between Low Carbohydrate Diet (LCD) and Calorie Restriction (CR)”. Asp Biomed Clin Case Rep, vol.2, no.s1: 4-15, 2019.

\section{Comparison on day 2 vs day 4:}

The levels of $M$ value on day 2 vs day 4 were compared in 4 groups (Fig-5). The median value in each group was 7.1 vs $10.5,39.7$ vs $5.0,139$ vs $15.7,367$ vs88, respectively. In group 1, the data of $M$ value was not changed. In group 2, 3, and 4, there was a remarkable decrease of $M$ value for 2 days.
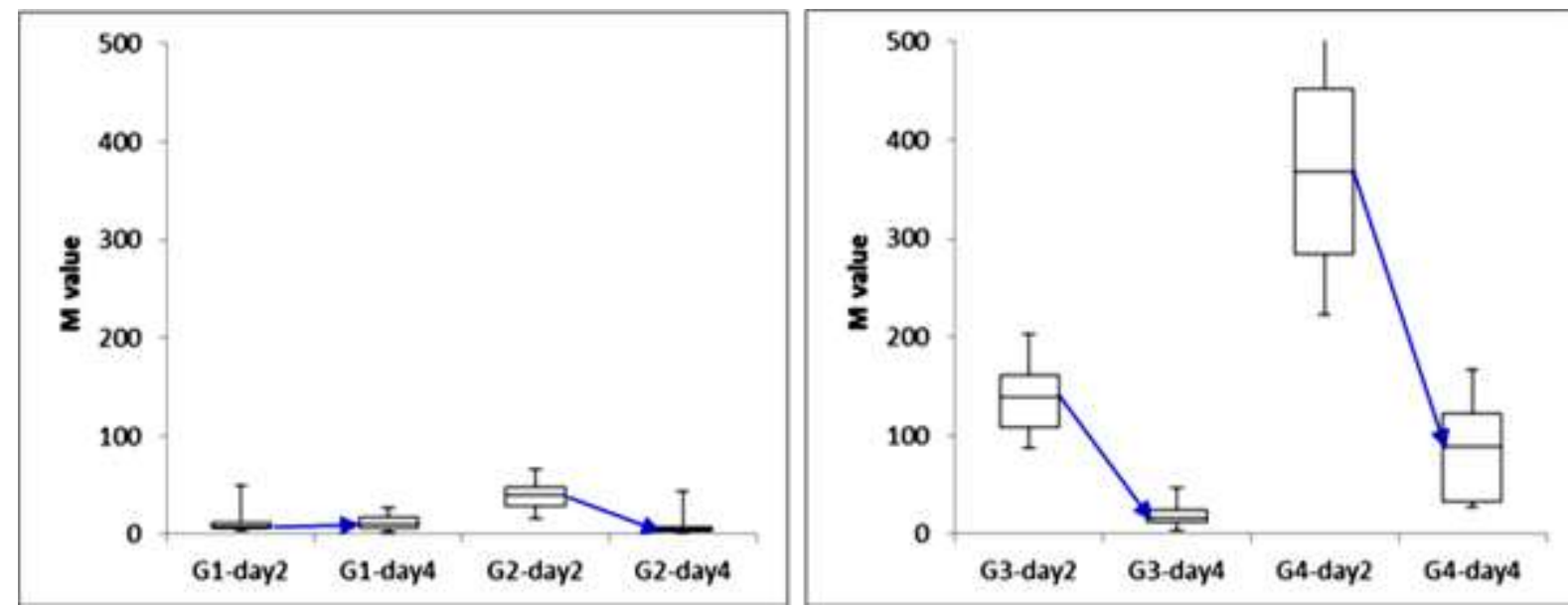

Fig 5: Changes in M value from day 2 to day 4 in 4 groups

Subjects have CR meal on day 1 and 2 and LCD on day 3-14. In group 1-4. M value decreased in 4 groups from day 2 to day 4.

\section{Correlation among biomarkers:}

Correlations of biomarkers among $\mathrm{HbA1c}, \mathrm{M}$ value, and average blood glucose were shown in Fig6. There are significant correlations between $\mathrm{HbA1c}$ and average blood glucose on day $2(p<0.01)$, and between $\mathrm{HbA} 1 \mathrm{c}$ and $\mathrm{M}$ value on day $2(\mathrm{p}<0.01)$.
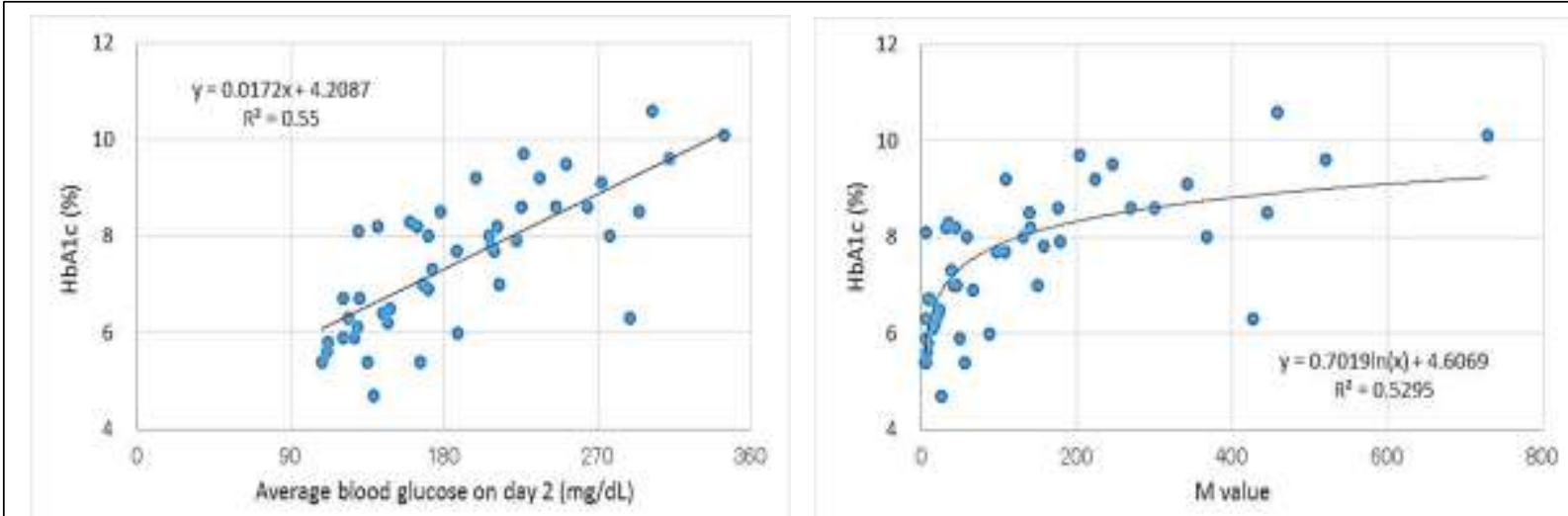

Fig- 6: Correlations of biomarkers HbA1c, M value and average blood glucose.

There are significant correlations between $\mathrm{HbA1c}$ and average blood glucose on day $2(p<0.01)$, and between $H b A 1 c$ and $M$ value on day $2(p<0.01)$.

Correlation between day 2 and 4 :

Correlations of the value of day 2 and day 4 in $M$ value and in average blood glucose were shown in Fig-7. There are significant correlations between the value of 2 and day 4 in average blood glucose $(p<0.01)$, and in $M$ value $(p<0.01)$. 
Citation: Bando H, Ebe K, Muneta T, et al., "Difference of Glucose variability between Low Carbohydrate Diet (LCD) and Calorie Restriction (CR)”. Asp Biomed Clin Case Rep, vol.2, no.s1: 4-15, 2019.
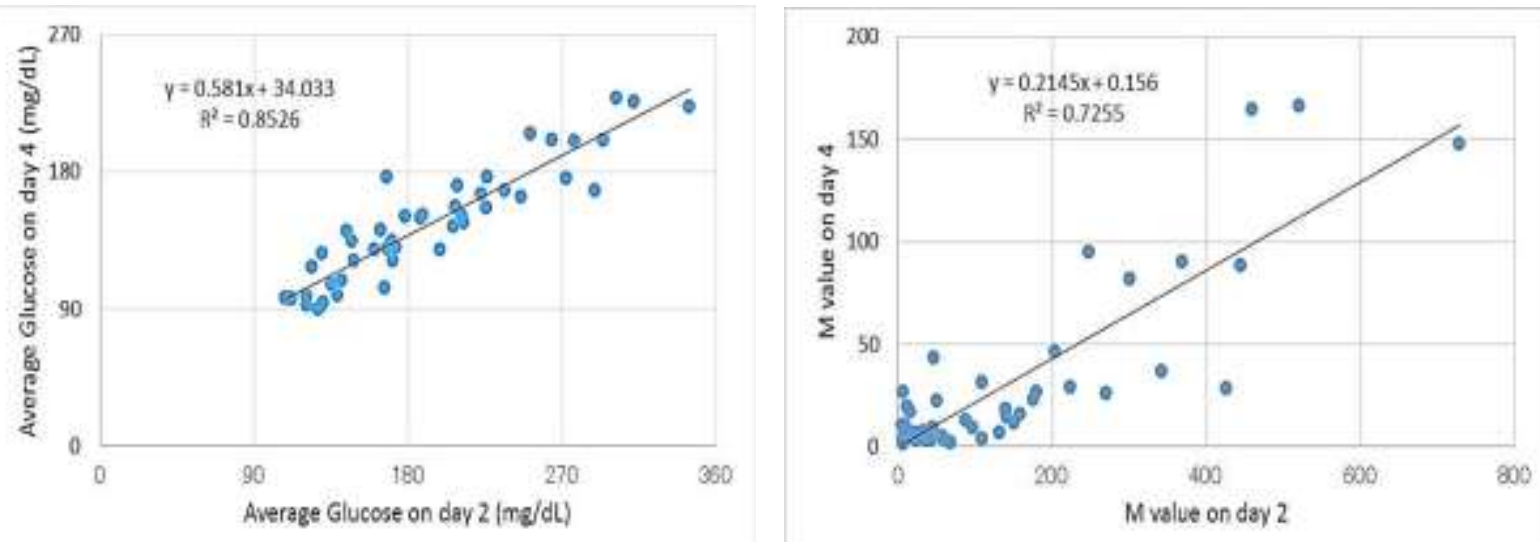

Fig- 7: Correlations of the value of day 2 and day 4 in M value and in average blood glucose.

There are significant correlations between the value of day 2 and day 4 in average blood glucose $(p<0.01)$, and in $M$ value.

\section{Discussion}

Regarding nutritional therapy for diabetes mellitus, clinical research for CR and LCD have been found for years $[11,14,23]$. For the development of LCD medically and socially, three types of LCD meals have been presented. They are super LCD, standard LCD, and petite LCD, which are including carbohydrate as the ratio of $12 \%, 26 \%$ and $40 \%$, respectively $[12,14]$. Actually, the type of LCD used in this study was super-LCD, which has evaluated as an effective LCD meal for obesity and diabetes $[24,25]$.

In the current study, glycemic variability on CR and LCD were measured and investigated. As to our protocol, we have had experiences of clinical research using CR meal and LCD meal [26]. By combined data of daily profile of blood glucose, $\mathrm{HbA1c}, \mathrm{M}$ value, a pathophysiological aspect of precise glucose variability would be clarified. The results of this study are obtained in Figures, which will be discussed in this order.

The attributes of the subjects in the 4 groups were not remarkably different. As a result of categorizing to 4 groups with mean blood glucose, the mean $\mathrm{HbA1C}$ and median $\mathrm{M}$ value seemed to be reasonable. On day 2 and 14, the TG value was remarkably decreased, which was the same tendency as previously reported $[25,27]$. On the other hand, there were no obvious changes in HDL and LDL.
Meals administered to the subjects were CR on days 1-2 and LCD on days 3-14. Only 24 hours after changing to LCD, glucose profile on day 4 was studied. Pre-prandial blood glucose levels on $0800 \mathrm{~h}, 1200 \mathrm{~h}$ and $1700 \mathrm{~h}$ were decreased dramatically on day 4 in comparison with those on day 2. Furthermore, postprandial blood glucose elevation on 1000h, 1400h, and 1900h was remarkably suppressed. Consequently, these changes seem to be clinically obvious effects of LCD.

The median values of $\mathrm{HbA1c}$ and $\mathrm{M}$ value increased similarly for groups 1 to 4 . As to $\mathrm{HbA1c}$, the overlapping area in each group was broad, whereas in $M$ value there were few overlapping regions and the distribution was rather distant from each other. This is one of the characteristic features of $M$ value [28]. When the level of blood glucose and MAGE become higher, the $M$ value will increase remarkably. Therefore, $M$ value seems to be clinically useful when we evaluate the glycemic variability. In other words, we can compare the difference between the diabetic cases, and also the difference of clinical course for a certain diabetic patient.

HOMA is an index calculated from the ratio of blood glucose level and insulin value [29]. There are two biomarkers, in which HOMA-R is related to insulin resistance and HOMA- $\beta$ is deeply related to insulin secretion ability [30]. From the results of this study, it is suggested that there 
Citation: Bando H, Ebe K, Muneta T, et al., "Difference of Glucose variability between Low Carbohydrate Diet (LCD) and Calorie Restriction (CR)”. Asp Biomed Clin Case Rep, vol.2, no.s1: 4-15, 2019.

may be a decrease in insulin secretion ability for groups 1 to 4 .

As to 4 groups, when comparing the average blood glucose on day 2 and 4, the apparent decrease was observed for 24 hours. The extent of the decrease was found small to larger in the order of the group 1 to 4 . In particular, group 4 showed a remarkable decrease in median average blood glucose level from $277 \mathrm{mg} / \mathrm{dL}$ to $201 \mathrm{mg} / \mathrm{dL}$ for 48 hours apart. As described above, LCD has clinically a hypoglycemic effect. As the initial blood glucose level is higher, there seems to be a tendency with larger decreasing effect.

For comparison of day 2 vs day 4 , mean blood glucose remarkably decreased in group 1-4. However, $M$ value in group 1 did not show a decline. The reason would be that the $M$ value becomes the minimum level when the blood glucose is around $120 \mathrm{mg} / \mathrm{dL}$, indicating almost zero [31]. Therefore, the mean blood glucose level decreased in group 1 , while the $M$ value did not show a decrease. On the other hand, $M$ value in group 3,4 decreased remarkably on day 4 than that of day 2. Compared to the decrease in mean blood glucose, the decrease of $M$ value seems to be very to large extent. This is a beneficial point of $M$ value, indicating both the mean blood sugar and mean amplitude of glycemic excursions (MAGE) [32]. Thus, M value would be useful in the comparative study.

There was a significant correlation between $\mathrm{HbA1c}$ and mean blood glucose on day 2 , with a high correlation coefficient as $R^{2}=0.55$. The obtained formula was $y=0.0172 x+4.2087$. Meanwhile, the standard formula reported by Nathan et al. has been known, which is average blood glucose level $(\mathrm{mg} / \mathrm{dL})=28.7 \times \mathrm{A} 1 \mathrm{c}(\%)-$ 46.7 [33].

Here, both formulas would be compared and calculated. For example, 3 cases are tried where the average blood glucose is $120 \mathrm{mg} / \mathrm{dL}, 150$ $\mathrm{mg} / \mathrm{dL}, 180 \mathrm{mg} / \mathrm{dL}$. Our formula showed $\mathrm{HbA} 1 \mathrm{c}=$ $6.2 \%, 6.8 \%, 7.3 \%$, respectively, and Nathan's formula showed $\mathrm{HbA} 1 \mathrm{c}=5.8 \%, 6.8 \%, 7.8 \%$, respectively. Both indicated the same value of $\mathrm{HbA1c}$ when the blood glucose is $150 \mathrm{mg} / \mathrm{dL}$. Regarding the inclination of the $\mathrm{HbA} 1 \mathrm{c}$ change, it is smaller in our equation and larger in Nathan's equation.

One reason would be the difference in the subjects. Our study covers 47 T2DM patients with a rather limited study. In contrast, Nathan et al. included thousands of normal individuals, diabetic patients with mild to severe range of subjects. It is inferred that the differences would be from this distribution difference in both.

There were significant correlations between $\mathrm{HbA1c}$ and $M$ value on day $2(p<0.01)$. The correlated pattern was not linear, but logarithmic distribution. Its characteristic points were rather different in each level as follows: i) $M$ value is rather low when $\mathrm{HbA1c}$ is about 5.0 $-7.0 \%$, ii) it increases abruptly when $\mathrm{HbA} 1 \mathrm{c}$ is $7.0 \%-8.0 \%$, iii) it is widely distributed when $\mathrm{HbA1c}$ is more than $8.0 \%$ [34]. From these findings, diabetic cases with $\mathrm{HbA} 1 \mathrm{c}$ value of more than $8.0 \%$ probably show wider glucose variability with average glucose and MAGE.

The average blood glucose between Day 2 and Day 4 showed a high correlation coefficient with $R^{2}=0.85$. The equation was $y=0.58 x+$ 34.0 , and we can speculate the average blood glucose of day 4 from the data on day 2. If the average blood glucose is $270 \mathrm{mg} / \mathrm{dl}$ on day 2 , the estimated value on day 4 is $191 \mathrm{mg} / \mathrm{dL}$. If it is $180 \mathrm{mg} / \mathrm{dL}$ on day 2 , it would $138 \mathrm{mg} / \mathrm{dL}$ on day 4 . Thus, the clinical effect of LCD can develop research possibility [25, 35].

Moreover, there was significant correlation of $M$ value between Day 2 and Day $4(p<0.01)$, with the equation as $y=0.21 x+0.16$, and $R^{2}=$ 0.73 . It showed the rapid decrease of $M$ value for only 2 days. This may be due to a sharp improvement in MAGE as well as decreased mean blood glucose. As described above, this effect is found only two days after the meal change from CR to LCD. Thus, the efficacy of LCD would be clinically remarkable in the light of glucose variability. 
Citation: Bando H, Ebe K, Muneta T, et al., "Difference of Glucose variability between Low Carbohydrate Diet (LCD) and Calorie Restriction (CR)”. Asp Biomed Clin Case Rep, vol.2, no.s1: 4-15, 2019.

\section{Conclusion}

In summary, 47 patients with T2DM were studied in the current report. We investigated diabetes-related biomarkers such as $\mathrm{HbA} 1 \mathrm{c}$, blood glucose, IRI, HOMA-R, HOMA- $\beta$, M value and lipids, and mutual correlations among them. Daily blood glucose on LCD showed decreased level compared with that of CR. Several significant correlations were found among diabetes-related biomarkers. These results suggest that LCD would be an effective nutritional therapy for improving glucose variability and that obtained findings would become a basal reference for future research development in this field.

\section{Acknowledgment}

Regarding this investigation, some part of the findings was presented at the Annual Conference of Japan Diabetes Society (JDS), Tokyo, Japan, 2018. The authors would like to express our sincere gratitude related staffs and patients for their understanding and cooperation.

\section{Conflicts Of Interest}

The authors state that we do not have any conflicts of interest in this report.

\section{References}

[1] Cho NH, Shaw JE, Karuranga S, et al., "IDF Diabetes Atlas: Global estimates of diabetes prevalence for 2017 and projections for 2045". Diabetes Res Clin Pract, vol.138: 271-81, 2018.

[2] Ogurtsova K, da Rocha Fernandes JD, Huang $Y$, et al., "IDF Diabetes Atlas: global estimates for the prevalence of diabetes for 2015 and 2040". Diabetes Res Clin Pract, vol.128: 40-50, 2017.

[3] American Diabetes Association (ADA), "Standards of Medical Care in Diabetes-2015". Diabetes Care, vol.38: S1-S2, 2015

[4] American Diabetes Association (ADA), "Pharmacologic Approaches to Glycemic Treatment: Standards of Medical Care in Diabetes-2018". Diabetes Care, vol.41, Suppl.1: S73-S85, 2018.

[5] American College of Physicians, "Clinical Guidelines and Recommendations", https://www.acponline.org/clinical- information/guidelines: 2018.

[6] Bando H, "Statement for Diabetes Guideline Has Been on Discussion for Future Better Lives". J Endocrinol Thyroid Res, vol.3, no.4: 555616, 2018

[7] Bernstein RK, "Dr. Bernstein's Diabetes

Solution: A Complete Guide to Achieving Normal Blood Sugars". Little, Brown and company, New York: 1997.

[8] Shai I, Schwarzfuchs D, Henkin Y, et al., "Weight Loss with a Low-Carbohydrate, Mediterranean, or Low-Fat Diet". N Engl J Med, vol.359, no.3: 229-41, 2008.

[9] Schwarzfuchs D, Golan R, Shai I "Four-year follow-up after two-year dietary interventions". $N$ Engl J Med, vol.367, no.14: 1373-74, 2012.

[10] Ebe K, Ebe $Y$, Yokota $S$, et al., "Low Carbohydrate diet (LCD) treated for three cases as diabetic diet therapy". Kyoto Medical Association Journal, vol.51: 125-29, 2004.

[11] Bando H, Ebe K, Muneta T, et al., "Effect of low carbohydrate diet on type 2 diabetic patients and usefulness of M-value". Diabetes Res Open J, vol.3, no.1: 9-16, 2017.

[12] Ebe K, Bando H, Yamamoto K, et al., "Daily carbohydrate intake correlates with $\mathrm{HbA} 1 \mathrm{c}$ in low carbohydrate diet (LCD)". J Diabetol, vol.1, no.1: 4-9, 2017

[13] Muneta T, Kawaguchi E, Nagai $Y$, et al., "Ketone body elevation in placenta, umbilical cord, newborn and mother in normal delivery". Glycative Stress Research, vol.3, no.3: 133-40, 2016.

[14] Bando H, Ebe K, Muneta T, et al., "Clinical Effect of Low Carbohydrate Diet (LCD): Case Report". Diabetes Case Rep, vol.2, no.2: 124, 2017.

[15] Japan Diabetes Association, "Diabetes clinical practice guidelines based on scientific evidence": 2013.

[16] Schlichtkrull J, Munck O, Jersild M, "The Mvalue, an index of blood sugar control in diabetics". Acta Med Scand, vol.177, no.1: 95102, 1965.

[17] Service FJ, Molnar GD, Rosevear JW, et al., "Mean amplitude of glycemic excursions, a measure of diabetic instability." Diabetes, vol.19, no.9: 644-55, 1970.

[18] Schlichtkrull J, Munck O, Jersild M, "Mvalue, an index for blood sugar control in 
Citation: Bando H, Ebe K, Muneta T, et al., "Difference of Glucose variability between Low Carbohydrate Diet (LCD) and Calorie Restriction (CR)”. Asp Biomed Clin Case Rep, vol.2, no.s1: 4-15, 2019.

diabetics". Acta Med Scand, vol.177: 815-20, 1964.

[19] Service FJ, Molnar GD, Rosevear JW, et al., "Mean amplitude of glycemic excursions, a measure of diabetic instability". Diabetes, vol.19, no.9: 644-55, 1970.

[20] Molnar GD, Taylor WF, Ho MM, "Day-to-day variation of continuously monitored glycaemia: $A$ further measure of diabetic instability". Diabetologia, vol.8, no.5: 342-48, 1972.

[21] Moberg E, Kollind M, Lins PE, et al., "Estimation of blood-glucose variability in patients with insulin-dependent diabetes mellitus". Scand J Clin Lab Invest, vol.53, no.5: 507-14, 1993.

[22] Yanai H, "Four steps excel statistics". Seiunsha Publishing Co.Ltd, Tokyo, 4th Edition: 2015.

[23] Tay J, Thompson CH, Luscombe-Marsh ND, et al., "Effects of an energy-restricted low carbohydrate, high unsaturated fat/low saturated fat diet versus a high-carbohydrate, low-fat diet in type 2 diabetes: A 2-year randomized clinical trial". Diabetes Obes Metab, vol.20, no.4: 85871, 2018.

[24] Meng Y, Bai H, Wang S, et al., "Efficacy of low carbohydrate diet for type 2 diabetes mellitus management: A systematic review and metaanalysis of randomized controlled trials". Diabetes Res Clin Pract, vol.131: 124-31, 2017.

[25] Feinman RD, Pogozelski WK, Astrup A, et al., "Dietary carbohydrate restriction as the first approach in diabetes management: Critical review and evidence base". Nutrition, vol.31, no.1: 1-13, 2015.

[26] Bando H, Ebe K, Muneta T, et al., "Urinary C-Peptide Excretion for Diabetic Treatment in Low Carbohydrate Diet (LCD)". Journal of Obesity and Diabetes, vol.1, no.1: 13-18, 2018.

[27] Accurso A, Bernstein RK, Dahlqvist A, et al., "Dietary carbohydrate restriction in type 2 diabetes mellitus and metabolic syndrome: time for a critical appraisal". Nutr Metab (Lond), vol.5, no.1: 1-9, 2008.

[28] Lee CL, Sheu WHH, Lee IT, et al., "Trajectories of fasting plasma glucose variability and mortality in type 2 diabetes". Diabetes Metab, vol.44, no.2: 121-28, 2018.

[29] Matthews DR, Hosker JP, Rudenski AS, et al., "Homeostasis model assessment: insulin resistance and beta-cell function from fasting plasma glucose and insulin concentrations in man”. Diabetologia, vol.28, no.7: 412-19, 1985. [30] Wallace TM, Levy JC, Matthews DR, "Use and abuse of HOMA modeling". Diabetes Care, vol.27, no.6: 1487-95, 2004.

[31] Nalysnyk L, Hernandez-Medina $M$, Krishnarajah G, "Glycaemic variability and complications in patients with diabetes mellitus: evidence from a systematic review of the literature". Diabetes Obes Metab, vol.12, no.4: 288-98, 2010.

[32] Siegelaar SE, Holleman F, Hoekstra JB, "Glucose Variability; Does It Matter?". Endocr Rev, vol.31, no.2: 171-82, 2010.

[33] Nathan DM, Kuenen J, Borg R, et al., "Translating the $\mathrm{A} 1 \mathrm{C}$ assay into estimated average glucose values". Diabetes Care, vol.31, no.8: 1473- 78, 2008.

[34] Lachin JM, Bebu I, Bergenstal RM, et al., "Association of Glycemic Variability in Type 1 Diabetes With Progression of Microvascular Outcomes in the Diabetes Control and Complications Trial". Diabetes Care, vol.40, no.6: 777-83, 2017.

[35] Gardner CD, Trepanowski JF, Del Gobbo LC, et al., "Effect of Low-Fat vs LowCarbohydrate Diet on 12-Month Weight Loss in Overweight Adults and the Association With Genotype Pattern or Insulin Secretion The DIETFITS Randomized Clinical Trial". JAMA, vol.319, no.7: 667-79, 2018.

Key Words: Glucose variability; Type 2 diabetes mellitus (T2DM); Low Carbohydrate Diet (LCD); Morbus value (M value); Calorie Restriction (CR). 